\title{
Comparative Analysis of Audience Perception of Globe FM (98.5) and Bauchi Radio Corporation's (BRC) Political Programs During the 2015 Presidential Election in Nigeria
}

\author{
Musa Alhaji Sale \\ MSc, Lecturer, Abubakar Tatari Ali Polytechnic Bauchi, Bauchi state, Nigeria
}

Abubakar Bappayo

MSc, Senior Lecturer, Abubakar Tatari Ali Polytechnic Bauchi, Bauchi state, Nigeria

\section{Ahmad Abubakar}

MSc, Lecturer, Abubakar Tatari Ali Polytechnic Bauchi, Bauchi state, Nigeria

\begin{abstract}
This study investigated the public perception of radio political programs of Globe FM and Bauchi Radio Corporation (BRC). The stations were owned by Federal and State governments respectively. The research method used in this study was a survey while the questionnaire was the instrument of data collection. The sample size was 384 respondents selected from Bauchi and Yobe States using a Creative Research Systems online sample size calculator by Wimmer and Dominick. The sampling technique was multi-stage. The results of this study found out that the respondents were exposed to political programs from Globe FM than they were to those from BRC. Further findings showed that the respondents perceived political programs from both Globe and BRC as very informative. Based on the result of this study, the researchers conclude that Globe FM was perceived to have done better than BRC in the area of political programs and recommends, among others, that radio political programs should provide sufficient information on the candidates' that can guide the public in their political decisions. The basic contribution of this study is that it has provided more understanding of public perceptions of radio political programmes. This understanding will provide a better insight into conception, design, planning, direction and execution of radio political programmes.
\end{abstract}

Keywords: comparative, audience, radio and politics.

\section{JEL Classification: Y.}

(C) The Authors, 2018. This article is published with open access at Sumy State University.

\section{Introduction}

Democracy thrives on elections as it is a political system that is governed by the rule and power of the majority. In addition to free and fair elections, an ideal democracy comes with other elements like the rule of law, which permits freedom of expression, among others, existence of political parties, universal adult suffrage and a free press (Jebril, Stetka \& Loveless 2013).

The current democratic dispensation in Nigeria has been the longest in the country's history having attempted some botched experiments between 1960-1966, 1979-1984 and 1990-1993. Since 1999, Nigerian democracy has been evolving and witnessing some salient transformations. For example, the People's Democratic Party (PDP) dominated the political scene for the first 16 years of the current dispensation; also the erstwhile uncoordinated opposition parties were able to form a united front that defeated the PDP. Another landmark event in the 2015 presidential election was the defeat of the sitting president, Dr. Goodluck Jonathan and swift acceptance of defeat which earned him and the country a great reputation.

The contributions of the media, particularly radio, during elections cannot be overemphasized. The more radio disseminated information and enlightenment on the relevance of political participation to the audience, the more interest, understanding and joy they derive from participating in it. Egbon (2002), opined that, to enhance an effective governance and societal welfare especially in the developing countries like Nigeria, radio has taken the lead amongst the mass media as the cheapest and most portable medium. Being the most effective medium for conveying citizens' problems to the government, radio also encourages and attracts development through mobilization, enlightenment and education by persuading population or inducing them to 
comprehensively participate in the democratic process. Radio in a democratic society, is always expected to provide platform where a broad range of political opinions, ideas, beliefs, thoughts, and behaviours from opposition parties, civil organizations, individual professionals and common citizens can suggest an alternative view. Hassan (2010) stated that, radio stands out as the most widely used among Nigerians especially in the rural areas. However, the attraction radio has derived for majority of the population from its cheap price and relatively low cost of operation. Radio sets are easily portable and can be used by the educated and unlettered. It is in recognition of the power of the radio that the federal and state government have established radio stations to broadcast in local and official languages and reach the citizens.

Therefore, to entrench effective governance and societal welfare, radio has taken the lead as the cheapest and portable medium being most effective as the vehicle for information and feedback system, playing a prominent role in aggregating opinions and contribution to policy formulation (Egbon, 2002). A survey conducted by the National Bureau of Statistics (2011) shows that $82.9 \%$ of Nigerians have access to radio. A breakdown of the figure reveals that only $53.3 \%$ have access to radio, and $30.6 \%$ owned radio as against $31.5 \%$ and $13.3 \%$ access and ownership of television respectively. In fact, radio breaks the barriers posed by literacy and poverty. For this reason, people tend to listen to radio more than they read newspapers and magazine, and more than they watch television. Consequently, individuals, interest groups and even governments have intensified efforts to own and control at least a radio station, with which to tell their own side of the story (Hassan, 2010). This among other reasons compelled Bauchi State government to establish its own radio station called Bauchi Radio Corporation (BRC).

Bauchi Radio Corporation (94.6) Amplitude Modulation (AM) formally called Bauchi Broadcasting Corporation (BBC) is a broadcast organization wholly owned by Bauchi State government of Nigeria, and established in 1977 barely a year after creation of the state, under then the Nigerian Broadcasting Corporation NBC, now known as Federal Radio Corporation of Nigeria (FRCN). As a matter of corporate policy, fundamental goals and objectives of Bauchi Radio Corporation primarily is to keep people of Bauchi State well-informed and educated on the activities, programs and other sundry matters of the government of Bauchi state as they directly affect the lives of millions of the population in the state (see www.brcbauchi.org.ng, 2016). The radio station had many political programs during the 2015 general election. Examples of such programs include: Maji Ma Gan, Maza Dangin Gurjiya and Gugar Karfe.

On the other hand, Globe Frequency Modulation 98.5 was among the FM stations established in 2007 with the name peal FM, when the Federal Radio Corporation of Nigeria (FRCN) began introducing FM transmitters in some locations with the aim of bringing information on government activities closer to the people.

The motive behind establishing of the radio station, as any other mass medium of communication, is to educate, inform and entertain. The emphasis largely revolved around creating awareness, surveillance of the environment, correlation of the parts of the society and transmission of cultural heritage (McQuail, 1998). In an effort geared toward actualization of these roles, radio producers came up with various political programs to quench the political thirst of audience. For instance, political programs like, Da Ba Zarku, Ga fili Ga Doki, and Ciki da gaskiya were aired on Globe FM Bauchi. In addition to these programs both stations broadcast other political messages through straight news, commercials and jingles. These programs always conveyed messages with the aims of socializing, mobilising and educating audience to actively participate in politics.

The purposes of initiating and executing these programs were mainly to satisfy the political needs of audience. McQuail (2000) described audience as the collective term for 'receivers' in mass communication process. In short, audience is a group of people, who listens or reads a particular media outlet. Audiences are made up of people who are different from each other, in a different perspective. These audiences' barriers may be political, economic, cultural, educational, psychological, ethnic, religious, physical or intellectual. The above wide diversity of backgrounds, behaviours, attitudes, skills and opinion made audience's perception of radio messages differ.

Perception is the interpretation attached to cognitions. Schacter (2011) described perception as the identification, arrangement and interpretation of sensory information in order to represent and understand the environment. Another psychologist, Pickens (2005) opined that, perception is the process by which organisms interpret and organize sensation to produce a meaningful experience of the world. Therefore, perception in this context refers to the process of interpreting political messages aired on radio stations. Before audience will form perception on political programs, there is need for proper enlightenment from radio being the most effective and accessible medium of communication. It is against this background that this study sought to determine 
audience perception of political programs of Globe FM 98.5 and Bauchi Radio Corporation during Nigeria's 2015 presidential election.

\section{Problem's statement}

Radio political programs are expected to inform and educate audience on political issues as well as guide them on how to take political decisions based on full information. Literature on the role of the radio as an instrument of political communication is voluminous and with little or no conflicting accounts. Scholars (e.g., Kombol, 2013; Oyesomi \& Okorie, 2013) have agreed that radio is a viable tool of electioneering campaigns. Suffice it to say that radio political programs are essential instruments of politicking, it follows logically that an understanding of audience exposure to the political programs and eventual perceptions about them is essential. Although previous studies (e.g. Obang, 2011; Umeh, 2011) have investigated audience exposure to radio political programs and audience perception, but still there is little or no evidence in literature on audience exposure and perceptions about radio political programs, especially in Northern Nigeria where radio is the major source of information (Egbon, 2002).

Radio bias featured seriously during the 2015 presidential campaigns; in that, some radio stations engaged in calumny and hate campaigns. Factors such as ownership, ethnicity, religion, cronyism and relatives appeared to dictate the tone and manner of packaging and airing of political programs and consequently limited the effectiveness of messages contained in these programs. It was observed that some people showed apathy to the electoral process and choose to remain mere spectators either because of lack of proper enlightenment from the radio or due to radio's inability to live up to expectation by being fair and objective in their reportage. Also problematic is scanty literature comparing audience exposure to and perceptions about radio political programs. Audience exposure to and perception about radio political programs from Globe FM (98.5) and Bauchi Radio Corporation (BRC), have not been clearly defined, hence the need for this study.

\section{Objectives of the study}

In a broader perspective the research is to analyse audience perception of political programs of Globe FM (98.5) and Bauchi Radio Corporation during the 2015 presidential election in Nigeria. This is due to the fact that the stations were owned by federal and state governments respectively and assumed to always project the interest of the owners. While the specific objectives include:

To ascertain the frequency of exposure to the political programs from Globe FM and Bauchi Radio Corporation during the 2015 presidential election among residents of Bauchi, and Yobe States.

To determine which political program (between Ga fili ga doki of Globe FM and Maji ma gani of BRC) audience perceive as more informative during the 2015 presidential campaigns.

\section{Research questions}

What is the frequency of exposure to the political programs from Globe FM and Bauchi Radio Corporation during the 2015 presidential election among residents of Bauchi and Yobe States?

Which political program (between Ga fili ga doki of Globe FM and Maji ma gani of BRC) do audience perceive as more informative during the 2015 presidential campaigns?

\section{Theoretical scope}

The democratic participant media theory was propounded by Dennis McQuail in 1987, it emerged in response to the elitists nature of the normative press, it responsiveness to political and economic pressure, the theory is associated in the developed liberal democracies in the world. The theory is against the commercialization and monopolization of privately owned media and against the centralism and bureaucratic of public media, as found in the social responsibility theory. Under this theory, the individual's right to communicate is defended, local organization and communities are encouraged to own their own channels of mass communication (McQuail, 2000).

\section{Literature review}

\section{Politics and the role of the media}

Politics thrives on the active participation of citizens; the depth of their participation is in turn determined by the quality of their political education or socialization. Although there are other agents of socialization like the 
family, school, peer group and religious institutions, the role of the mass media in political socialization stands out unique. Through news items, commentaries, documentaries, interviews, visuals and other contents, the audience is exposed to political orientation while also granted the liberty to make informed choices (Oso, Soola \& Pate, 2012).

According to Suleiman (2002) mass media serve in a democracy as the vital links between initiators, implementers and consumers of public policies. The mass media convey information to the electorate from politicians and vice versa. This information is very crucial for the electorates to make informed choices. Similarly, the media enable government and politicians to get direct access to the people, across geographical and psychological barriers. Media are vital instruments in democratization, especially during election campaign or voter mobilization. In fact, it is very difficult to have a free and democratic society without vibrant mass media. In the same vein, McNair (2002) opined that "In democratic political systems, media function both as transmitters of political communication which originates outside the media organization itself and as senders of political messages constructed by journalists" McNair further listed five functions of the mass media in a democratic society as follows;

Mass media must inform citizens of what is happening around them (what Lasswell, 1948 described as "surveillance" or monitoring" functions of the media).

The media should also give publicity to government and political institutions.

The media in democratic societies serve as a channel for advocacy of political viewpoints. Parties require an outlet for the articulations of their policies and programs to a mass audience and thus the media must be open to them.

According to Obot (2013), "Democracy presumes an open state in which people are allowed to participate in decision making, and are given access to the media, and other information networks through which advocacy occurs. Hallin and Paolo, (2004) explained that in political markets, electorates need information to hold government accountable of its actions and to reward or punish those in authority. If electorate are poorly informed, or if they lacked practical knowledge, they may end up electing leaders that are not true reflection of their interest. Moreover, policymakers need reliable information about population, to respond to public anxieties, to deliver effective services, to meet the societal needs, and also in democracies to maximize popular electoral support to be returned to office.

In buttressing the above statement Nwokeafor and Okunoye (2013) stressed that there is a strong consensus of a pivotal role for the mass media in politics and political participation. They also raise the question of media and power processes in the society while accentuating the assumption that the media are structures of power in any society. Experts are unanimous on the pivotal role played by the media in shaping politics and mobilizing for political participation. There is also the consensus of opinion on the fact that the media are structures of power in any society, those who control power own the media and vice versa. Nigeria's political history will be incomplete without prominent mention of the mass media. During the struggle for independence by Country's founding fathers, newspapers were established as part of mobilization tools in confronting the colonial masters. "In Nigeria, the mass media since its inception in 1935 have played significant roles in shaping the social and political landscape and setting the agenda for the country's political development" (Zahid, 2012).

In tracing the evolution of broadcasting in Nigeria, Udeajah (2004) described 1951-1962 as the nationalist's experimentation because it was the period when the nationalists exhaustively used the media in seeking and obtained independence in Nigeria. Nwokeator and Okunoye, (2013) also note that" during the era of military dictatorship, the Nigerian media also rose gallantly to the occasion as the major opposition and dissenting voice to the various governments held political power intermittently between 1966-1999". Olukotun, (2005) further said that, some of the prominent political developments in Nigeria's current democratic dispensation that have been influenced by media discourse include, the aborted third term agenda by former president Obasanjo, issues revolving around the illness of late President Umaru Musa Yaradua, the swearing in of the then Vice President Jonathan as the substantive president; managing the 2011 post-election violence, enlightenment campaign on the new innovation of smart card readers and permanent voters cards, campaigns against the dictatorial tendencies of the Buhari's regime and the health issues of Muhammadu Buhari. Olukotun, (2005) is of the view that these and a few other events have been the dominant political communication issues in Nigeria since the return of democratic rule over seventeen years ago. 
Election in a democratic setting affects everyone directly or indirectly and the expectation is that whenever there is a fair, balanced and inclusive participation of all people in the election of leaders without discrimination on grounds of sex, ethnicity, religion, tribe or any other factor, the society will progress. Achieving inclusive participation during elections requires the media. Section 0.2.2.4 of the Nigeria Broadcasting code (2012) states that the aims of the broadcast media is to contribute to the development of National unity and participatory democracy; while the political objective of broadcasting are to create and encourage political awareness among the population in order to achieve a democratic society, inculcate in the people, the spirit of tolerance of all shades of opinion and promote social justice based on the responsibilities and rights of individuals in society. Olukotun $(2014$, p. 3) supports this notion when he stated that during elections, the media are the principal tools where the constituencies obtain information concerning the aspirants, political parties, their platform, the voting process etc. The electoral commission exploited media in educating voters. Pate, (2011) continued that the media functions in the public scope to enlarge the boundaries of freedom of expression and allow the populations to have access to the credible information that will help them to make an informed decision for sustainable democracy. No channel of Mass Communications is left out as they are all actively engaged in gathering analysing and disseminating issues about elections. In fact, media can be referred to as oxygen of democracy. Pate (2011, p. 2) further quoting McQuail, (2005) enumerated five critical institutions necessary for credible election as thus, the mass media, the electoral commission, the political parties and candidates, the police, the judiciary.

Popular leaders and credible representatives emerge from fair, balanced and inclusive participation of the citizens and this is enhanced when the electorate is empowered with valid information.

Radio stations ease spreading of information on electoral process through provision of medium to individuals or groups who do not have access to other media. Through radio, politicians can disseminate their political opinions to a wider and larger audience. Equally, government uses radio to educate the population on new government policies and other developmental issues. Oso, Soola and Pate, (2012) stated that, radio has always provided a fast, cheap channel to reach the government and for the government to reach the people. Both the poor and rich can hear radio programs. Radio has the possibility of contributing toward achieving developmental programs and can be used in sustaining free society.

Ace (2012) opined that, the radio serves as a watchdog over the government by keeping people informed on all actions of government. Hence, the media, to be precise (radio) plays a vital role in keeping the citizenry abreast of contemporary issues and improving awareness of various events. It also has an extremely significant impact on the public's opinion and way of thinking. The radio is the primary means through which public opinion is shaped and at times manipulated. Laura (2007) opined that in an era of timeliness and demand for information, the radio plays a central role in updating the public about politics, campaigns and elections. Laura observed that there is a cyclical relationship between radio, the government and the public; radio always serves as public opinion moulders, it keeps people informed on the entire electoral process. It emphasized that radio works more effectively by placing attention on certain issues that affected the larger society.

\section{Empirical studies}

A number of studies have been conducted on the correlation between radio and political mobilization in different parts of the world. Didiugwu, Okwudiri, Apeh and Odoh (2014) used Explanatory Sequential mixed methods design to collect both quantitative and qualitative data and studied Federal Radio Corporation of Nigeria political program (Nnọko Umunwanyi program ). Questionnaire was used to collect quantitative data while focus group discussion was used to generate qualitative data. The study was conducted in Anambra and Enugu states and findings showed that women in Enugu State are exposed to Nnọko Umunwanyi program to a large extent. It was equally found that the knowledge and women participation in politics have increased as a result of their exposure to the program . This study, though relevant because it investigated radio political program, the sample was limited to only women.

Amponsah (2012) examines the coverage of general presidential campaigns by the Daily Graphic (a Ghanaian newspaper) concerning the National Democratic Congress (NDC) and the New Patriotic Party (NPP) from 1992-2004. The researcher adopted content analysis to achieve its aim. The results showed that discussion of candidates' policy positions receives more attention than discussion of their character. Positive statements (acclaims) are the most common function in the news stories, followed by negative comments (attacks), and then defenses. Candidates represent the most common sources for the statements in the articles, followed by 
reporters, supporters, and others. Implications of these results on Ghana as an emerging democratic country are discussed. This study is relevant to the current one because electioneering was the major focus.

Porath, Suzuki and Ramdohr (2015) investigated the evolution of political campaign coverage through a content analysis of the topics highlighted in newspapers' agendas during three presidential elections in Chile. Results showed an expected increase in the space allocated to the politicians' private lives (privatization) by 2009 , but no change in the attention given to individual politicians' political traits (political competence). Coverage of candidates' campaign strategies had increased markedly in media agendas by 1999, and by 2009 in politicians' agendas.

This work focused on 2015 presidential election campaigns which took place between November 16th, 2014 to February 12th, 2015 (90 day plus additional six weeks of postponement). It was geared toward investigating how information from radio affected political orientation and voting behaviour of audience during the 2015 presidential election. The study differed from the previous studies in terms of area and scope of the study, population, media out-pit and period of the study.

\section{Methodology}

\section{Design of the study}

Survey Research method was considered most appropriate because it was a type of research method that allowed researchers to investigate problems that have to do with eliciting responses from human beings.

\section{Population of the study}

The Independent National Electoral Commission (INEC) has released the total of 3,154,095 as the registered voters for these states during the 2015 voter's registration exercise as thus: Bauchi State has 2,054,125 voters and Yobe State has 1,099,970 voters. In view of the foregoing, the population of this study is 3,154,095 eligible voters of Bauchi and Yobe States during the 2015 general elections.

\section{Sample size}

In determining the sample size for this study, the Wimmer and Dominick Creative Research Systems online sample size calculator was employed. The sample size calculator allows the researchers to calculate the required responding sample size, standard error, and a confidence interval (95\% or 99\%) for a proportion estimate, using just one of these criteria as an input. The estimated variance proportion was $0.5(5 \%)$, the confidence interval was set at $5 \%$, the confidence level was $95 \%$. The total population of this study was $3,154,095$ which was the registered voters for the affected states during the 2015 voter's registration exercise as thus: Bauchi State has 2,054,125 voters and Yobe State has 1,099,970 voters.

Therefore the sample size of 384 were drawn from the population of 3,154,095 using the above Creative Research Systems online sample size calculator by Wimmer and Dominick with confidence level of $95 \%$ and confidence interval of 5.0.

\section{Sampling technique}

Multi-stage sampling technique was used in reaching the target respondents. It encompasses a combination of cluster, purposive, simple random and quota sampling techniques.

Stage One: The population was divided using cluster sampling technique into 37 clusters, that is, the thirty seven (37) Local Government Areas of the two selected states, thus: Bauchi State comprises 20 Local Government Areas as follows: Alkaleri, Bauchi, Bogoro, Dambam, Darazo, Dass, Gamawa, Ganjuwa, Giade, Itas/Gadau, Jama'are, Katagum, Kirfi, Misau, Ningi, Shira, Tafawa Balewa, Toro, Warji and Zaki Local Givernment Areas, while the remaining 17 Local Government Areas belong to Yobe state thus: Bade, Bursari, Damaturu, Fika, Fune, Geidam, Gujba, Gulani, Jakusko, Karasuwa, Machina, Nangere, Nguru, Potiskum, Tarmuwa, Yunusari and Yusufari Local Government Areas.

Stage Two: From the above 37 clusters (LGAs), the researcher used purposive sampling technique and selected two Local Government Areas (clusters) one local Government Area from each state based on areas covered by the signals of the Globe FM and Bauchi Radio Corporation. The selected LGAs are Ganjuwa LGA from Bauchi State and Potiskum LGA from Yobe State. 
Stage Three: In the third stage, three Registration Areas (Wards) were selected from each local government area using simple random sampling technique and the selected wards are presented in the table below.

Table 1. Tabular Presentation of the Sampling Procedure

\begin{tabular}{|l|l|l|}
\hline \multicolumn{1}{|c|}{ States Under Study } & \multicolumn{1}{|c|}{ Selected LGAs } & \multicolumn{1}{c|}{ Selected Wards } \\
\hline Bauchi & Ganjuwa & Kafin Madaki, Kariya and Miya East \\
\hline Yobe & Potiskum & Bolewa "A", Dogo Nini and Mamudo \\
\hline
\end{tabular}

Source: INEC (www.inecnigeria.org.ng).

Stage Four: Quota sampling technique was used in selecting 192 respondents from each Local Government Area. The respondents are registered members of Radio Listeners Associations in the affected Local Government Areas.

\section{Measuring Instrument}

Because of the nature of the study and the research design adopted, the researcher used questionnaire as measuring instrument. This instrument was considered very appropriate because it helped to generate data for quantitative analysis which was found very useful in addressing the objectives of this study. The questionnaire was used in sampling the opinions of the 384 selected respondents from the population.

\section{Method of Administering Instrument}

The questionnaire was administered with the help of two research assistants who are residing in the two selected LGAs. They were trained on how to effectively administer the instrument. Before embarking into the field work proper a pilot study was conducted to assess the competency and understanding of the instrument by the research assistants.

\section{Reliability of Measuring Instrument}

The reliability of the instrument is the degree to which the questionnaire can yield consistent results when the study was replicated. Pilot study was carried out in Birnin Kudu LGA of Jigawa State which did not form part of the study. Forty (40) selected residents of Birnin Kudu town were selected for the pre-test because they shared common culture with people of Bauchi and Yobe states. The data obtained from the pre-test was analysed using Cronbach's Alpha method and $92 \%$ or 9.2Co-efficient level was attained which made the instrument reliable.

\section{Validity of Measuring Instrument}

To ensure clarity, appropriateness of language, and expressions in fulfilling the objectives of the study, the questionnaire was first validated by two lecturers in the Department of Mass Communication, University of Nigeria Nsukka. Content validation was thereafter done by one lecturer in the Department of Measurement and Evaluation of the University of Nigeria Nsukka. The project supervisor then provided further guidance before the final test instrument was administered.

\section{Method of Data Analysis}

The data generated through the questionnaire were collated, presented and analysed using frequency tables, simple percentages and the Scientific Package for Social Science (SPSS). Therefore, the researcher used descriptive data analysis with mean and standard deviation in analysing the data.

\section{Data presentation, analysis and interpretation}

\section{Demographic data}

The demographics characteristics of the respondents are presented below:

Table 2. Respondents' gender distribution

\begin{tabular}{|l|c|c|}
\hline & Frequency & Percentage \\
\hline Male & 232 & 63.9 \\
\hline Female & 131 & 36.1 \\
\hline Total & 363 & 100.0 \\
\hline
\end{tabular}


The result from the table above showed that most of the respondents were males. The dominance of male respondents in the sample was not deliberate but the outcome of the study. This dominance could be as a result of the location as women are more reserved in Northern Nigeria than other parts of the country.

Table 3. Respondents' age

\begin{tabular}{|l|c|c|}
\hline \multicolumn{1}{|c|}{ Age } & Frequency & Percentage \\
\hline $18-24$ & 86 & 23.7 \\
\hline $25-29$ & 29 & 8.0 \\
\hline $30-34$ & 216 & 59.5 \\
\hline $35-39$ & 20 & 5.5 \\
\hline 40 and above & 12 & 3.3 \\
\hline Total & 363 & 100.0 \\
\hline
\end{tabular}

The result from the table above showed that most of the respondents (216 or 59.5\%) were within the age bracket of 30-34. This implies that most of the participants were mainly youth and are likely to be interested in politics and radio political programs.

Table 4. Respondents' marital status

\begin{tabular}{|l|c|c|}
\hline \multicolumn{1}{|c|}{ Marital status } & Frequency & Percentage \\
\hline Married & 225 & 62.0 \\
\hline Single & 101 & 27.8 \\
\hline Divorced & 25 & 6.9 \\
\hline Widowed & 12 & 3.3 \\
\hline Total & 363 & 100.0 \\
\hline
\end{tabular}

The result from the table above showed that most of the study sample (225 or 62.0) were married. This is not surprising because of the prevalence of early marriage in northern Nigeria.

Table 5. Respondents' occupation

\begin{tabular}{|l|c|c|}
\hline \multicolumn{1}{|c|}{ Occupation } & Frequency & Percentage \\
\hline Civil servant & 180 & 49.6 \\
\hline Trading & 90 & 24.8 \\
\hline Farming & 20 & 5.5 \\
\hline Housewife & 43 & 11.8 \\
\hline Student & 25 & 6.9 \\
\hline Unemployed & 5 & 1.4 \\
\hline Total & 363 & 100.0 \\
\hline
\end{tabular}

From the table above, it can be seen that most of the respondents ( 180 or $49.6 \%$ ) were civil servants only few of the respondents were house wives. This could be because of the nature of the Northern Nigeria where majority of the elites are government workers.

Table 6. Respondents' educational level

\begin{tabular}{|l|c|c|}
\hline \multicolumn{1}{|c|}{ Educational level } & Frequency & Percentage \\
\hline Primary level & 60 & 24.8 \\
\hline Secondary level & 67 & 18.5 \\
\hline Tertiary level & 206 & 56.7 \\
\hline Total & 363 & 100 \\
\hline
\end{tabular}

The result from the table above showed that most of the respondents (206 or 56.7\%) had tertiary education. What this means is that most of the respondents are educated enough to interpret media messages.

Research Question 1: What is the frequency of exposure to political programs from Globe FM and Bauchi Radio Corporation during the 2015 general election? 
Table 7. Respondents' radio ownership

\begin{tabular}{|l|c|c|}
\hline \multicolumn{1}{|c|}{ Responses } & Frequency & Percentage \\
\hline Yes & 337 & 92.8 \\
\hline No & 26 & 7.2 \\
\hline Total & 363 & 100.0 \\
\hline
\end{tabular}

The result from the table above revealed that most of the respondents had radio set. Only a negligible portion reported that they had no radio set of their own. It should be noted that lack of ownership does not equal to no exposure as people could listen to radio through those of their friends, or families. The next table determined exposure to political programs on radio.

Table 8. Respondents' Exposure to political programs of Globe FM and BRC

\begin{tabular}{|l|c|c|}
\hline \multicolumn{1}{|c|}{ Responses } & Frequency & Percentage \\
\hline Yes & 340 & 93.7 \\
\hline No & 23 & 6.3 \\
\hline Total & 363 & 100.0 \\
\hline
\end{tabular}

The result from the table above suggests that $93.7 \%$ of the respondents reported that they are exposed to political programs of Globe FM and BRC during the 2015 general elections. What this means is that most of the respondents were exposed to political programs from both radio stations and could develop perception about such programs. In determining the frequency of exposure to political programs from both stations, 23 respondents who reported that they are not exposed to political programs from Globe FM and BRC were excluded.

Table 9. Mean scores of the respondents on exposure to Globe FM and BRC political programs

\begin{tabular}{|l|c|c|c|c|}
\hline \multicolumn{1}{|c|}{ Radio Stations } & Respondents & Mean & Std. Deviation & Std. Error Mean \\
\hline Globe FM & 340 & 1.5265 & .82505 & .04474 \\
\hline BRC & 340 & 1.2706 & .68938 & .03739 \\
\hline
\end{tabular}

Research Question 2: Which political program (between Ga fili ga doki of Globe FM and Maji ma gani of BRC) do audience perceive as more informative during the 2015 presidential campaigns?

Table 10. Respondent' listenership of Ga fili ga doki of Globe FM and Maji ma gani of BRC

\begin{tabular}{|l|c|c|}
\hline \multicolumn{1}{|c|}{ Responses } & Frequency & Percentage \\
\hline Very often & 338 & 99.4 \\
\hline Sometime & 2 & 0.6 \\
\hline Not at all & 0 & 0 \\
\hline Total & 340 & 100.0 \\
\hline
\end{tabular}

Result from the above table indicated that majority of the respondents (338 or $99.4 \%$ ) exposed themselves to Ga fili ga doki of Globe FM and Maji ma gani of BRC and only negligible number (2 or $0.6 \%$ ) listened to these programs occasionally. This may not be unconnected with the relevance the politicians and the general public attached to these programs in quenching their political needs.

Table 11. Whether Respondents noticed any differences between Ga fili ga doki of Globe FM and Maji ma gani of BRC on how they reported the 2015 presidential campaigns

\begin{tabular}{|l|c|c|}
\hline \multicolumn{1}{|c|}{ Responses } & Frequency & Percentage \\
\hline Yes & 184 & 54.1 \\
\hline No & 145 & 42.6 \\
\hline Can't say & 11 & 3.3 \\
\hline Total & 340 & 100.0 \\
\hline
\end{tabular}

Result from the above table showed that most of the respondents (184 or $54.1 \%$ ) noticed differences in the way and manner the two political programs (Ga fili ga doki of Globe FM and Maji ma gani of BRC) were packed and aired during the 2015 presidential electioneering. Although the differences are very slim as reasonable number of the respondents (145 or 42.6) contended that there is no difference on the way these programs covered the 2015 presidential election. These differences could be as a result of ownership factor as most of the radio stations always dance to the tone of their proprietors. 
Table 12. Program provided more information on presidential candidates during the 2015 presidential election

\begin{tabular}{|l|c|c|}
\hline \multicolumn{1}{|c|}{ Responses } & Ga fili ga doki of Globe FM & Maji ma gani of BRC \\
\hline Yes & $116(34.1 \%)$ & $88(25.9 \%)$ \\
\hline No & $224(56.9 \%)$ & $252(74.1 \%)$ \\
\hline Total & $340(100 \%)$ & $340(100 \%)$ \\
\hline
\end{tabular}

Result from the table above revealed that most of the respondents reported that both Ga fili ga doki of Globe FM and Maji ma gani of BRC did not provided sufficient information on the presidential candidates during the 2015 presidential election. Comparatively, Ga fili ga doki of Globe FM provided more information on the candidates than Maji ma gani of BRC

Table 13. Political program respondents perceived to have provided more information on previous records of the presidential candidates

\begin{tabular}{|l|c|c|c|}
\hline \multicolumn{1}{|c|}{ Responses } & Ga fili ga doki of Globe FM & Maji ma gani of BRC & Total \\
\hline Yes & $150(44.1 \%)$ & $130(38.2 \%)$ & $280(82.4 \%)$ \\
\hline No & $190(55.9 \%)$ & $25(7.4 \%)$ & $60(17.6 \%)$ \\
\hline Total & $185(54.4 \%)$ & $155(45.6 \%)$ & $340(100.0 \%)$ \\
\hline
\end{tabular}

The cross tabulation of the above table showed that most of the respondent perceived that both Ga fili ga doki of Globe FM and Maji ma gani of BRC did not provided them with enough information on previous records of the presidential candidates during the 2015 presidential election. Comparatively, Ga fili ga doki of Globe FM performed better.

Table 14. Political program audience perceived to have provided more information on candidates' political parties

\begin{tabular}{|l|c|c|c|}
\hline \multicolumn{1}{|c|}{ Responses } & Ga fili ga doki of Globe FM & Maji ma gani of BRC & Total \\
\hline Yes & $155(45.6 \%)$ & $116(34.1 \%)$ & $271(79.7 \%)$ \\
\hline No & $45(10.3 \%)$ & $24(7.1 \%)$ & $69(20.3 \%)$ \\
\hline Total & $200(58.82 \%)$ & $140(41.17 \%)$ & $340(100.0 \%)$ \\
\hline
\end{tabular}

The results from the table above showed a complete departure from the previous tables. The respondents perceived the political programs from both radio stations as largely providing enough information on the political parties. This could be because of the heated politicking that took place during the 2015 electioneering; especially the muscle flexing between the All Progressives Congress (APC) and the then ruling party, People Democratic Party (PDP). Comparatively, Ga fili ga doki of Globe FM did better in this regards.

\section{Discussion}

The result of this study showed that most of the respondents studied were exposed to political programs from Globe FM and BRC very often during the 2015 presidential election. This could be as a result of the fact that both Globe FM and Bauchi Radio Corporation during the 2015 presidential election were airing most of their political programs from Monday to Friday. The result of this study is consistent with that of Didiugwu, Okwudiri, Apeh and Odoh (2014) who after a study of FRCN Enugu's Nnọko umunwanyi political program, reported that 262 respondents representing $69.3 \%$ were exposed to the program. Similarly, 203 respondents representing 53.7 per cent of the entire respondents said that they have been listening to Nnoko Umunwanyi program on FRCN Enugu. The result is also consistent with that of Abubakar (2011, p.10) who revealed in his study that, Yobe State women were exposed to women political programs on the broadcast media which encouraged them to participate in electoral process by registering and voting. Frequency of exposure to political programs is essential in determining perception.

\section{Summary, conclusion and recommendations}

\section{Summary}

The results of this study suggest that most of the respondents studied were exposed to political programs from Globe FM and BRC very often within the election period. The respondents perceived political programs from Globe FM as more informative than those from BRC. Finally, results showed that most of the respondents perceived political programs from Globe FM as more powerful in changing political attitude than those from BRC. 


\section{Conclusion}

Based on the findings of this study, the researchers conclude that most of the sample from Yobe and Bauchi States were exposed to political programs from Globe FM and BRC very often within the election period hence they developed perceptions from these programs. The study concludes that political programs from Globe FM and BRC were perceived as powerful enough to influence political behaviour but Globe FM fared better than BRC.

\section{Recommendations}

The recommendations are principally for the various stakeholders among who are the media professionals particularly Journalists, media managers, government and researchers in this field of study.

Based on the findings, it is recommended that radio political programs should provide enough information on candidates manifestoes, abilities and previous records to the public instead of undue concentration on political parties as this will guide the voter to choose the most qualified candidate.

The BRC needs to improve on its political programs because it was poorly rated by the public.

Further studies should be conducted to determine other factors that influence public perception of political programs from radio and other media of mass communication.

\section{References}

1. Abubakar, L.A. (2011). The role of radio in mobilizing the northern women for participation in the 2011 INEC voter's registration. Journal of Media, Politics, 2(3), 21-39.

2. Ace (2012). The ACE Encyclopaedia: Media and Elections the electoral media network. Retrieved from www.aceproject.org.

3. Aghadiegwe, C.U. (2013). Broadcasting Industry in Nigeria: Growth and Perspectives. In Okoro, N. Contemporary Readings in Media and Communication Studies (pp. 68-96). Lagos: St. Benedette Publishers LTD.

4. Akubor (2015). Campaigns and Electioneering: Reflecting on the 2015 General Elections in Nigeria: Paper presented at the Two-Day National Conference on "The 2015 General Elections in Nigeria: The Real Issues" Organized by the Electoral Institute, Abuja. Venue: Electoral Institute Complex, INEC Annex, Opposite Diplomatic Zone, Central Business District, Abuja. 26th - 29th July, 2015.

5. Amponsah, N. (2012). The Daily Graphic coverage of presidential campaigns in Ghana, 1992-2004. Journal of Political Science, Government and Politics, 1(2), 1-15.

6. Arogundade, L. (2014). "The Nigerian Media Code of Election Coverage". Presented at stakeholders meeting on the Media Code of Election Coverage/Media Tool kit for the Elections", held at Regent Luxury Hotel, GRA Ikeja, Lagos, 29 October.

7. Asemah, E. S. (2011). Selected mass media themes. Jos: Jos University press.

8. Brcbauchi (2016). www.brcbauchi.com, retrieved on 27th September, 2016.

9. Baran, S. J. and Davis D. K. (2003). Mass Communication Theory: Foundations, Ferment, and Future. Belmont (USA): Thomas-Wardworth.

10. Didiugwu, I., Okwudiri, O., Apeh, A. \& Odoh, V. (2014). New Media and Mass Communication, 32, 7081. Dealing with our apathy through the radio: analysis of the role of FRCN Nnọko Umunwanyi program in influencing women to participate in politics

11. European Union (2015). Election Observation Mission. Final Report of the Nigeria General Elections of 28th March, 2015, 11th April, 2015. Submitted, July 2015.

12. Hallin, D. C., \& Paolo, M. (2004). Americanization, Globalization and Secularization: Understanding the Convergence of Media Systems and Political Communication. In F. Esser, \& B. Pfetsch (Eds.). Comparing Political Communication: Theories, Cases and Challenges. Cambridge. Cambridge University Press.

13. Hasan, S. (2010). Mass Communication: Principles and Concepts. New Delhi: Satish Kumar Jain.

14. Ifeanyi, A. L., Martins, O. P. and Alexander, O. C. (2012). The Mass Media, Gender Balance and Politics in Nigeria: An Assessment. An International Journal of Language, Literature and Gender Studies (AFRREV LALIGENS), 1(3), 14-35.

15. Independent National Electoral Commission (INEC). www.inecnigeria.org.ng.

16. Kombol, A. M (2013). Obstacles to Digitising State owned Radio. A Study of Radio Benue. KSU Journal of Mass Communication, 1(2), 103-188. 
17. Laura, L. (2007). The Influence of the Media in Politics, Campaigns and Elections Retrieved from Retrieved http://voices.yahoo.com/the-influence-media- politics-campaigns-and.

18. McNair, B. (2002). An Introduction to Political Communication. New York: Routledge.

19. McQuial, D. (1987). Mass Communication Theories: An Introduction. London: Sage Publication.

20. McQuail, D. (1998). Mass communication theories: An introduction. London: Sage Publication.

21. McQuial, D. (2000). Mass Communication Theories: An Introduction. London: Sage Publication.

22. Nancy, N. I. (2014). Influence of ownership in radio news coverage. (A Study of Federal Radio Corporation of Nigeria, Enugu. (Unpublished Project) Caritas University, Amorji Nike, Enugu.

23. National Broadcasting Commission. (2010). Nigeria Broadcasting Code 5th Edition Section.

24. National Bureau of Statistics, (2011). Annual socio-economic report, access to ICT. Viewed $12^{\text {th }}$ August, 2014 from www.nigerianstat.gov.ng/pages/download/35.

25. Nwigwe, B. N. (2013). Impact of Salt FM radio on political mobilization of the people of Ezza North LGA of Ebonyi State. Unpublished Dissertation, Caritas University, Amorji Nike, Enugu.

26. Obang,G. D.(2011). The use of radio in mobilizing women for the 2011 INEC voter's registration in cross river state. Journal of Media and Politics, 3(1), 34-48.

27. Obot, C. (2013). Mass Media Electioneering Campaign and Uyo (Nigeria) Voters' Decision During 2011 General Elections, Journal of Politics and Law; 6(1). Retrieved on 15th August, 2016. doi:10.5539/jpl. v6n1p173.

28. Okwuchukwu, O. G. (2014). The Influence of Media Ownership and Control on Media Agenda Setting in Nigeria. International Journal of Humanities Social Sciences and Education (IJHSSE), 1(7), 36-45, Retrieved on 15th August, 2016 www.arcjournals.org.

29. Olukotun, A. (2005). Repressive state and resurgent media under Nigeria's military dictatorship, 1988 98. Ibadan, College Press and Publishers Limited.

30. Olukotun, A. (2014). Welcome address/contextual overview of the workshop Presented at the 2-day training workshop on „Reporting Elections: A Non-Partisan Approach" held at the Conference Centre, University of Ibadan, Monday \& Tuesday, 15 \& 16 December.

31. Oso, L. Soola, O. Pate, U. (2012). Media, Governance and Development in Nigeria: Issues and Trends. Germany: LAP LAM BERT Academic Publishing GmbH \& Co. KG.

32. Oyesomi, K. \& Okorie, N. (2013). Radio and political mobilisation of women in Ado-odo/Ota local government of Ogun State. Global Journal of Applied, Management and Social Sciences, 195 - 205.

33. Pate, U. A. (2011). Media and the Process of Democratization in Nigeria. A paper presented at a Workshop on the Media and Democracy in Nigeria organized by the INEC Press Corps held at Kaduna, December 15-17.

34. Suleiman, B. (2002). Gender, Media and Democracy: Strategies for Women's Political Empowerment and Participation. National Conference on Democracy and Democratization in Nigeria: An Assessment of the Period 1999-2001. Organized by The Centre for democratic Research and Training, Mambayya House, Bayero University Kano, (177-201). Kano: Benchmark Publisher.

35. Wimmer, R. D. and Dominick, R. J. (2003). Mass Media Research: An Introduction. Singapore, Thomson Asia pte Ltd.

36. Wimmer, R. D. and Dominick, R. J. (2016). Online Sampling Calculator.

37. Umeh, J. T. (2011). women and radio broadcasting in the age of digitalization. International Journal of Gender and Security Studies, 14(14), 12-27.

38. Zahid, Y. (2012). Private Television Channels as an Agent of Political Awareness in Pakistan, Interdisciplinary Journal of Contemporary Research in Business, 4(3), 87-106. 
Appendix

\section{Sample Size Calculator}

Confidence Level: $\quad \bigcirc 95 \% \bigcirc 99 \%$

Confidence Interval (\%): 5

Population size:

Do not use commas

\section{5}

\section{Calculate}

\section{Clear}

Sample size needed:

384

\section{Steps}

1. Confidence Level: Click desired level

2. Confidence Interval: Enter \%, such as 4.9 or $\mathbf{5 . 0}$

3. Population: Enter size if finite; otherwise, leave blank.

4. Hit calculate button

\section{Return to Wimmer Dominick}

Figure 1. Mass Media Research: An Introduction - Roger D. Wimmer \& Joseph R. Dominick - Sample Size Calculator 